\title{
Synthetic Glycomacromolecules of Defined Valency, Absolute Configuration, and Topology Distinguish between Human Lectins
}

Manuel Hartweg, ${ }^{\dagger}$ Yivan Jiang, ${ }^{\dagger}$ Gokhan Yilmaz, Cassie M. Jarvis, Hung V.-T. Nguyen, Gastón A. Primo, Alessandra Monaco, Valentin P. Beyer, Kathleen K. Chen, Somesh Mohapatra, Simon Axelrod, Rafael Gómez-Bombarelli, Laura L. Kiessling,* C. Remzi Becer,* and Jeremiah A. Johnson*

Cite This: JACS Au 2021, 1, 1621-1630

ABSTRACT: Carbohydrate-binding proteins (lectins) play vital roles in cell recognition and signaling, including pathogen binding and innate immunity. Thus, targeting lectins, especially those on the surface of immune cells, could advance immunology and drug discovery. Lectins are typically oligomeric; therefore, many of the most potent ligands are multivalent. An effective strategy for lectin targeting is to display multiple copies of a single glycan epitope on a polymer backbone; however, a drawback to such multivalent ligands is they cannot distinguish between lectins that share monosaccharide binding selectivity (e.g., mannose-binding lectins) as they often lack molecular precision. Here, we describe the development of an iterative exponential growth (IEG) synthetic strategy that enables facile access to synthetic glycomacromole-

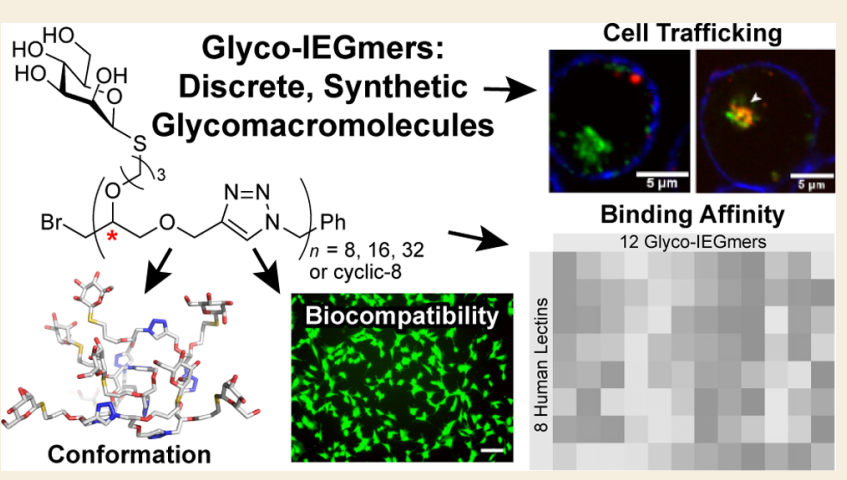
cules with precisely defined and tunable sizes up to $22.5 \mathrm{kDa}$, compositions, topologies, and absolute configurations. Twelve discrete mannosylated "glyco-IEGmers" are synthesized and screened for binding to a panel of mannoside-binding immune lectins (DCSIGN, DC-SIGNR, MBL, SP-D, langerin, dectin-2, mincle, and DEC-205). In many cases, the glyco-IEGmers had distinct length, stereochemistry, and topology-dependent lectin-binding preferences. To understand these differences, we used molecular dynamics and density functional theory simulations of octameric glyco-IEGmers, which revealed dramatic effects of glyco-IEGmer stereochemistry and topology on solution structure and reveal an interplay between conformational diversity and chiral recognition in selective lectin binding. Ligand function also could be controlled by chemical substitution: by tuning the side chains of glycoIEGmers that bind DC-SIGN, we could alter their cellular trafficking through alteration of their aggregation state. These results highlight the power of precision synthetic oligomer/polymer synthesis for selective biological targeting, motivating the development of next-generation glycomacromolecules tailored for specific immunological or other therapeutic applications.

KEYWORDS: glycopolymer, lectin, IEG, discrete oligomers, click chemistry, precise polymer, stereochemistry, mannose

\section{INTRODUCTION}

Since their discovery in $1888,{ }^{1}$ carbohydrate-binding proteins (lectins) have emerged as vital regulators of biological processes, including cell recognition, signal transduction, and

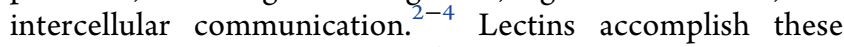
functions by binding glycans (oligosaccharides, polysaccharides, glycolipids, etc.) on the surfaces of cells or viruses. ${ }^{5-9}$ Many of these interactions are directly involved in human disease. Thus, there is a great desire for synthetic glycan probes to engage specific lectins for cell targeting or inhibition. Nevertheless, devising ligands that interact selectively with lectins is challenging. Lectins have evolved to act on target cells, viruses, or glycoproteins through multivalent binding. Accordingly, most lectins are oligomeric. As a result, they typically bind weakly to monovalent glycans; therefore, efforts to generate specific lectin ligands are focused on multivalent glycoconjugates. $^{10-12}$

Although multivalent glycans often bind avidly, their ability to distinguish between lectins that bind similar monovalent sugars is limited. Many reports on the design of multivalent ligands rely on statistical polymers, whose epitope density, length, or stereochemistry are not precisely defined. ${ }^{13,14}$ Thus, their presentation of glycan-binding epitopes with different geometries and orientations may preclude selective binding. We postulated that discrete synthetic glycomacromolecules with precise absolute configurations could bind lectins with

Received: June 9, 2021

Published: August 10, 2021

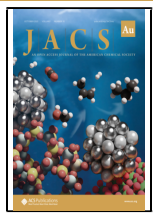


A
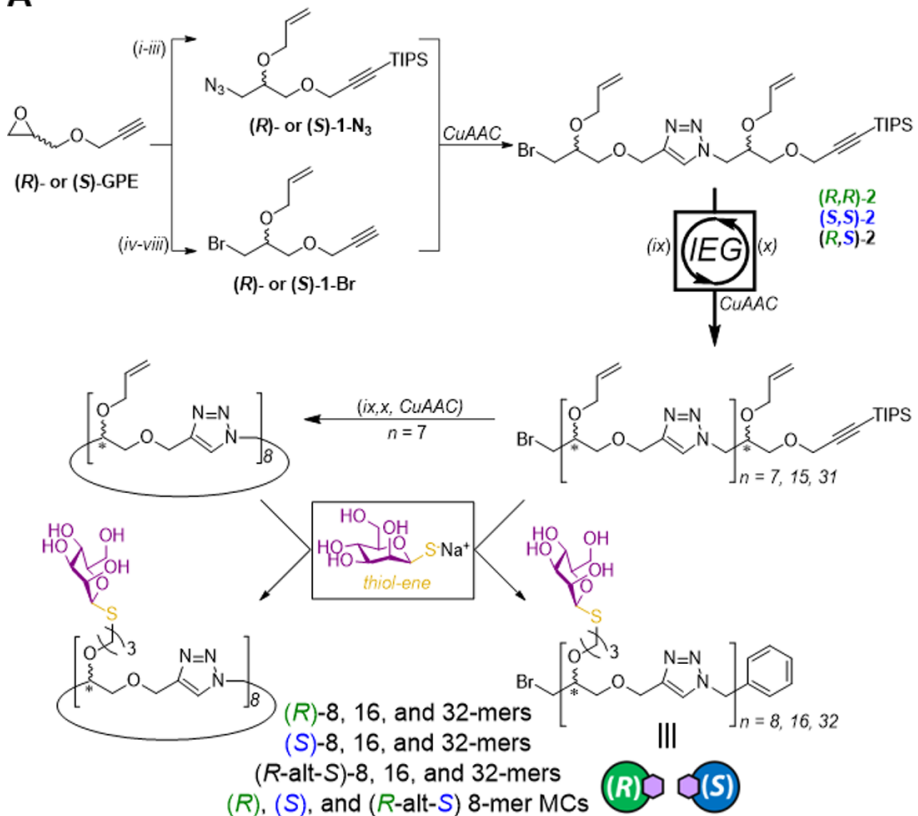

9 stereo-defined linear $\beta$-mannosylated glyco-IEG-mers \& 3 cyclic glyco-IEG-mers
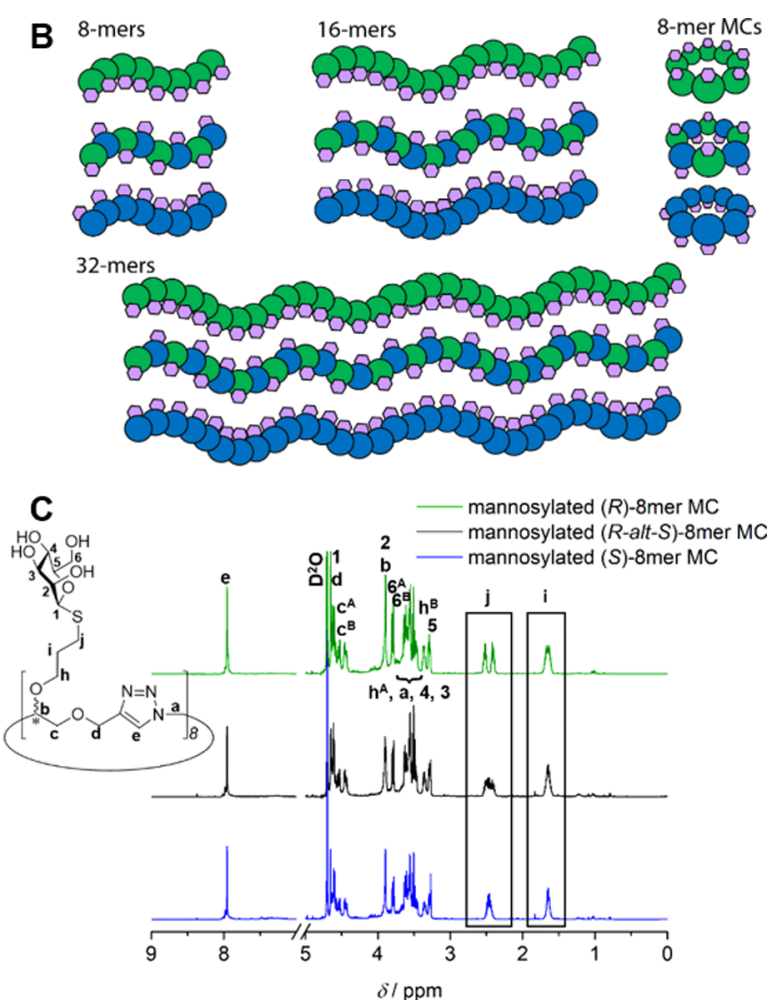

Figure 1. Synthesis of glyco-IEGmers. (A) IEG strategy toward allyl-functionalized macromolecules and subsequent formation of $\beta$-mannosylated glyco-IEGmers; a (i) $n$-BuLi then TIPS-Cl, THF, $-78^{\circ} \mathrm{C}$ to rt, 4 h, $85-86 \%$; (ii) $\mathrm{NaN}_{3}$, AcOH, DMF, $70{ }^{\circ} \mathrm{C}, 80 \%-82 \%$; (iii) allyl-Br, $\mathrm{NaH}$, DMF, $0{ }^{\circ} \mathrm{C}$ to rt, $16 \mathrm{~h}, 70-80 \%$; (iv) $t$ - $\mathrm{BuOH}, \mathrm{Mg}\left(\mathrm{ClO}_{4}\right)_{2}$, rt, $72 \mathrm{~h}, 91 \%$; (v) allyl-Br, $\mathrm{NaH}, \mathrm{DMF}, 0{ }^{\circ} \mathrm{C}$ to rt, $16 \mathrm{~h}, 90-92 \%$; (vi) $\mathrm{H}_{3} \mathrm{PO}_{4}(85 \%), \mathrm{rt}, 4 \mathrm{~h}$, 78\%-80\%, (vii) TsCl, DMAP, $\mathrm{Et}_{3} \mathrm{~N}, \mathrm{CH}_{2} \mathrm{Cl}_{2}, 0^{\circ} \mathrm{C}$ to rt, 78\%-84\%, (viii) $\mathrm{LiBr}, \mathrm{DMF}, 45^{\circ} \mathrm{C}, 16 \mathrm{~h}, 86-88 \%$; (ix) TBAF, THF, $15 \mathrm{~min}$; (x) NaN ${ }_{3}$, DMF, $35{ }^{\circ} \mathrm{C}, 16 \mathrm{~h}$; typical CuAAC: $\mathrm{Cu}(\mathrm{MeCN})_{4} \mathrm{PF}_{6}$, TBTA, sodium ascorbate, $\mathrm{CH}_{2} \mathrm{Cl}_{2}$; typical thiol-ene: 1-thio- $\beta$-D-mannose sodium salt, DMPA, DMF, conc. HCl in DMF, $\lambda=365 \mathrm{~nm}, 6 \mathrm{~h}, 35-77 \%$. (B) Schematic representation of 12 glyco-IEGmers synthesized in this study. These macromolecules vary in their cyclic vs linear topology, absolute configuration, and length. (C) ${ }^{1} \mathrm{H}$ NMR characterization $\left(500 \mathrm{MHz}, \mathrm{D}_{2} \mathrm{O}, 25^{\circ} \mathrm{C}\right.$, $400 \mathrm{MHz}$ ) of diastereomeric mannosylated 8-mer macrocycles.

higher and/or tunable selectivity. Our hypothesis is rooted in the knowledge that the distances and orientations between glycan-binding sites on oligomeric lectins are defined. ${ }^{15,16}$ Currently, the synthesis of molecularly defined synthetic and natural glycomacromolecules is challenging, precluding facile exploration of structure-selectivity space.

There are no readily accessible biological expression systems or amplification methods that can produce appreciable quantities of pure glycans with systematic structural variations. ${ }^{17}$ Synthetic glycomacromolecules, on the other hand, can be synthesized readily using statistical polymerization methods and postpolymerization modification. ${ }^{18-23}$ Such glycomacromolecules can block hemagglutinin on influenza $\mathrm{A},{ }^{24-27}$ inhibit $\mathrm{HIV}$ binding to DC-SIGN on dendritic cells, ${ }^{22,28-34}$ or trigger immunological responses for vaccine development. ${ }^{35-38}$ Though these systems are valuable, they are generated using stochastic processes that lack precise control over stereochemistry, length, and sugar epitope density. Current methods for preparing uniform, synthetic glycomacromolecules are generally based on strategies that are costly to scale; they typically require complex protecting group manipulations, large excesses of reagents, and laborious purifications. Efforts toward synthesizing more well-defined synthetic glycomacromolecules have been reported via solution phase $^{39-42}$ and solid-phase methods. ${ }^{43-46}$ Nevertheless, given that the scaffold upon which a glycan epitope is presented is critical for activity, ${ }^{47}$ general strategies for the scalable, facile synthesis of precise glycomacromolecules are needed.
Iterative exponential growth (IEG) offers a powerful strategy for the synthesis of discrete oligomers and polymers with tunable sequences and absolute configurations and good scalability. ${ }^{48-50}$ In IEG, orthogonally functionalized (macro)molecules undergo cycles of activation and convergent coupling. IEG has enabled detailed studies of the impact of molecular features on materials, including block copolymer self-assembly, cell uptake, and in vivo biodistribution. ${ }^{51,52} \mathrm{We}$ reasoned that IEG might enable the synthesis of glycomacromolecules that could selectively target distinct lectins and potentially reveal molecular trends related to lectin binding that would be impossible to unveil with stochastic polymers. To this end, our goal here is to introduce a new synthetic platform for precision glycopolymer synthesis that enables absolute control of molecular structure. We leveraged IEG to prepare a set of allyl-functionalized oligo/polymers of varied lengths $(8,16$, and 32 allyl side chains), topologies (linear or cyclic), and absolute configurations. Subsequent thiol-ene addition reactions using thiol-mannose provided access to 12 distinct mannosylated "glyco-IEGmers" (Figure 1A, B). Assessment of the binding specificity of these glycomacromolecules toward different mannose-binding lectins revealed structure-dependent binding preferences that would be obscured using traditional statistical polymer mixtures. To the best of our knowledge, no prior studies have screened discrete, synthetic glycopolymers in this manner. Our results open the door to the potential identification of new strategies for highly selective targeting of mannose-binding lectins and 

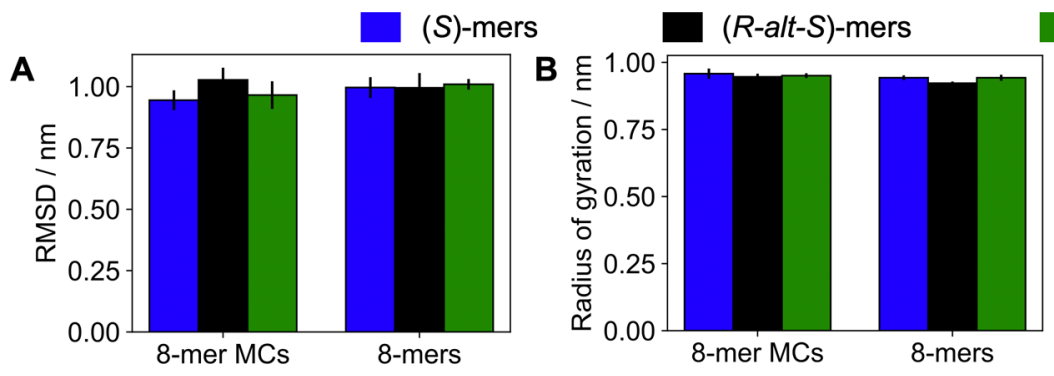

$(R)$-mers

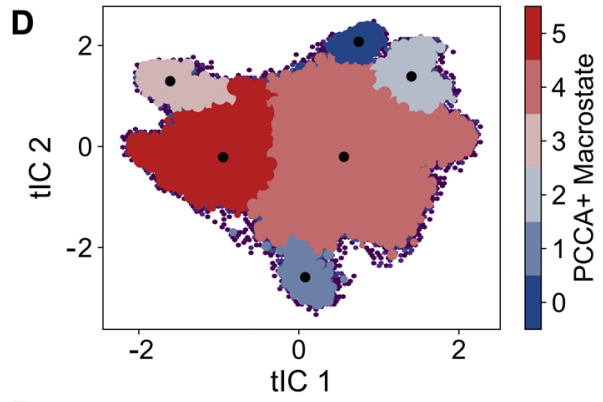

E
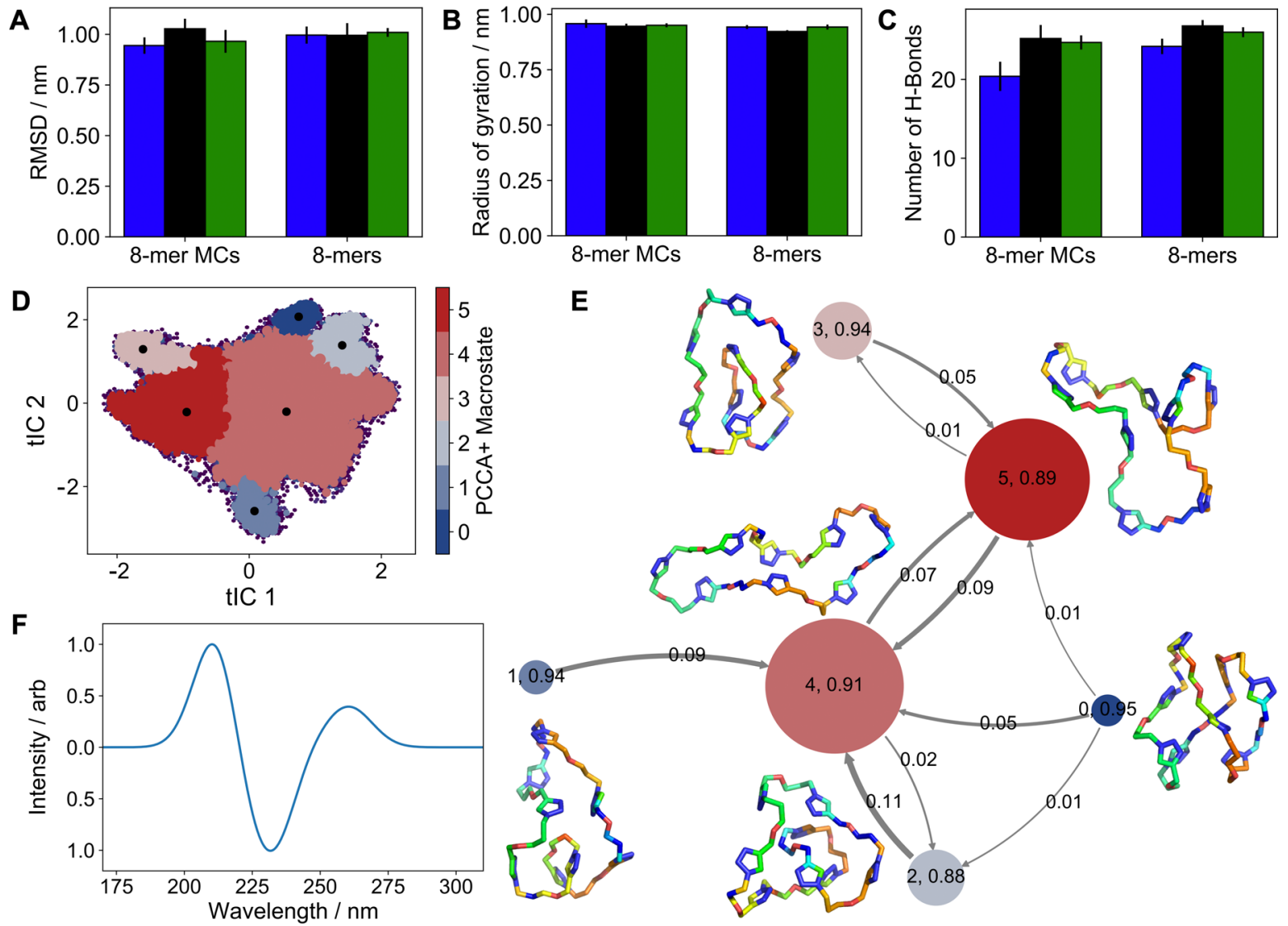

Figure 2. Molecular dynamics simulation trajectories for $(S)$, (R-alt-S), and (R) macrocyclic and linear 8-mers. (A) Root-mean-squared deviation, (B) radius of gyration, and (C) number of hydrogen-bonds, are similar across most systems. The peaks and error bars denote the average and standard deviation of mean values across different replicates, respectively. (D) Macrostate Markov state model (MSM) for (R-alt-S) 8-mer MC shows 6 macrostates for this system. Microstates corresponding to the macrostate are colored as such. This plot is overlaid on the two-component tIC plot for (R-alt-S) 8-mer MC. (E) Transition network demonstrates how the glyco-IEGmer backbone for (R-alt-S) 8-mer MC transitions in and out of open and looped conformations. In the network, nodes are macrostates and arrows denote the direction of transition. Node diameter is proportional to the population of the respective macrostate. Arrow thickness is proportional to the transition probability. The probabilities are noted as the numbers over the arrows and nodes. The color scheme for the nodes corresponds to the PCCA+ macrostates in D. The conformations depicted correspond to the adjacent nodes, and are indicated by the black dots in D. The coloring of the carbon atoms is consistent across all conformations and indicates the presence of different triazole units in the loop in different macrostates. (F) Ab initio simulated CD spectrum of $(R$ alt-S) 8-mer MC shows the presence of a secondary structure, in agreement with the experimental results (Figure S36).

will motivate the development of next-generation precise glycomacromolecules as therapeutics and tool compounds for glycobiology.

\section{SYNTHESIS AND CHARACTERIZATION}

To generate the target mannosylated glyco-IEGmers, IEG cycles beginning from $(R)$ - or $(S)$-glycidyl propargyl ether (GPE, > 99\% ee) were conducted to yield oligo/polytriazoles with precisely 8,16 , or 32 allyl side chains. Macromolecules were produced with three different overall absolute configurations: all $(R)$ ("isotactic"), all $(S)$ ("isotactic"), and alternating (R-alt-S) ("syndiotactic") (Note: absolute configurations are labeled based on the GPE enantiomer used). The three stereoisomeric 8-mers were subsequently cyclized at high dilution to provide macrocyclic isomers of their linear counterparts. To append the mannose residues, we exposed each of these 12 allyl-based oligo/polymers to pure $\beta$ thiomannose sodium salt under UV light $(\lambda=365 \mathrm{~nm})$, affording the glycoconjugates in quantitative yield. The stereochemistry was preserved, as indicated by the sharp signals in ${ }^{1} \mathrm{H}$ NMR spectra of the glyco-IEGmers (Figure 1C;
Figures S23-27) and 1D and 2D NMR analyses of a model thiol-ene reaction using $\beta$-thiomannose and allyl alcohol (Figures S10-13). ${ }^{1} \mathrm{H}$ NMR analysis of diastereomeric glycoIEGmers revealed their unique chemical environments. For example, for the isotactic $(S)$-8-mer macrocycle (Figure 1C), the signals from protons $\mathrm{H}^{\mathrm{i}}$ and $\mathrm{H}^{\mathrm{j}}$ are the narrowest, whereas the corresponding signals from the syndiotactic macrocycle are broader. By contrast, the signals for the same protons of the isotactic (R)-8-mer macrocycle are broader yet $\left(\mathrm{H}^{\mathrm{i}}\right)$ or split into two distinct multiplets $\left(\mathrm{H}^{\mathrm{j}}\right)$.

\section{CONFORMATIONAL ANALYSIS}

Circular dichroism (CD) spectroscopy showed that the chiral secondary structures of the glyco-IEGmers changed with topology, length, stereochemistry, and solution $\mathrm{pH}$ (Figure S36). Molecular dynamics (MD) simulations of the linear and macrocyclic 8-mer glyco-IEGmers suggest that they have rich and complex solution structures arising from their topologies and configurations. Few marked differences were seen in the ensemble-average root-mean-squared-deviation, radii of gyration, and numbers of intramolecular hydrogen bonds (Figure 

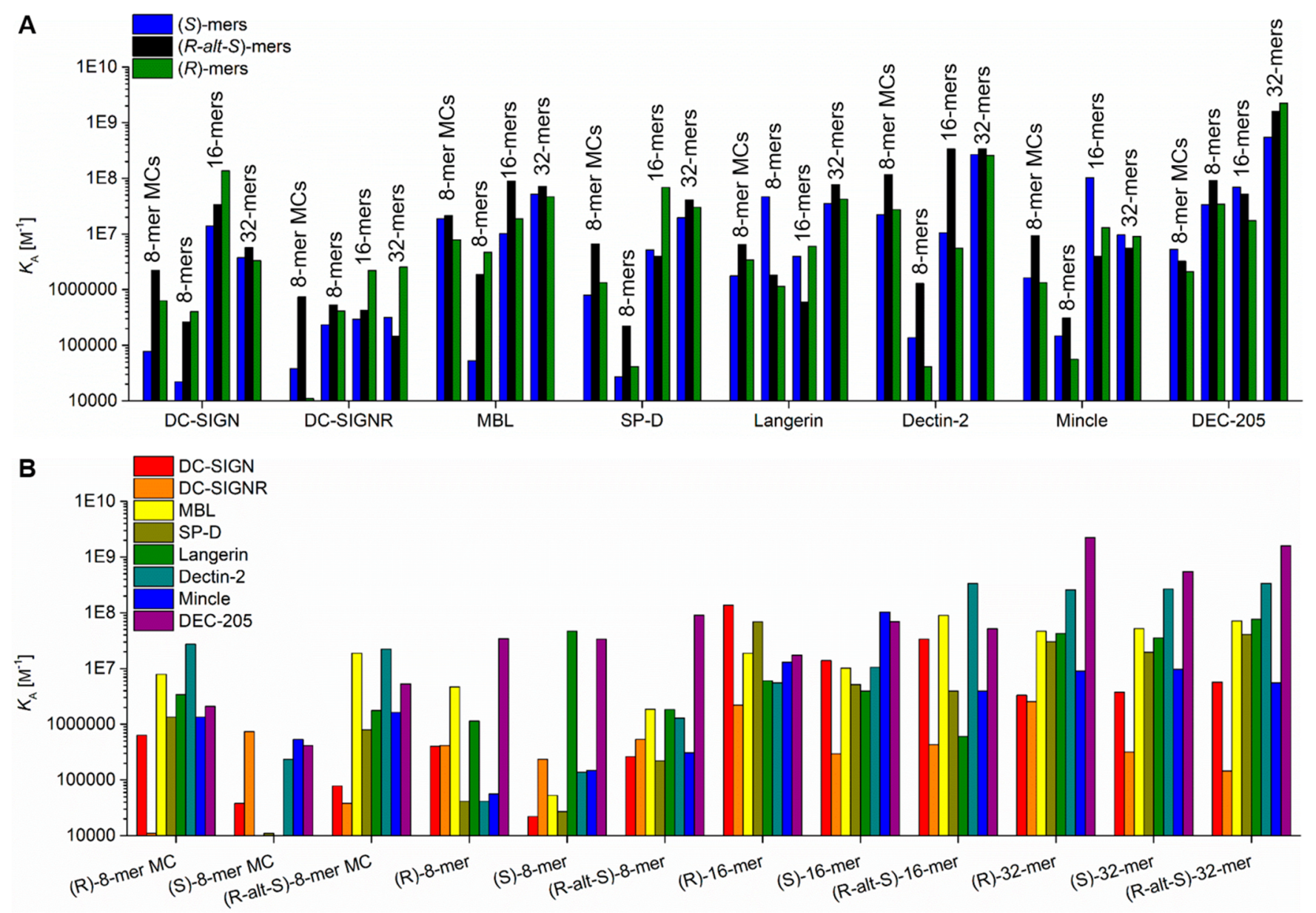

Figure 3. Summary of association constants $K_{\mathrm{A}}\left(\mathrm{M}^{-1}\right)$ between eight lectins (DC-SIGN, DC-SIGNR, MBL, SP-D, langerin, dectin-2, mincle, and DEC-205) and the 12 synthesized glyco-IEGmers (8-mer MCs, linear 8-mers, 16-mers, and 32-mers). (A) $K_{\mathrm{A}}$ values grouped by lectins. (B) $K_{\mathrm{A}}$ values grouped by glyco-IEGmer.

2A-C). However, dynamical analysis of the MD data identifies multiple interconverting long-lived substates for each isomer. (Figure 2D,E; Figures S47-S52). The macrocycles were comparatively more rigid, adopting discrete longer-lived conformational substates with different degrees of backbone looping and twisting. The states of the linear chains have variable degrees of structure and coiling. The $R$-alt-S isomers typically had more complicated conformational profiles than either the $R$ or $S$ diastereomers. Separate analyses of the backbone and mannose side chain motions (Figures S54-S59) suggest that the long-lasting conformational states are mostly associated with the backbone; the mannose units rapidly fluctuate around their backbone anchor points.

Using the solution structure from MD simulations, ab initio CD spectra were simulated. The optical properties of the backbone repeat unit were calculated from density functional theory and combined with excitonic modeling. The results (Figure 2F, Figure S53) generally agree with the experimentally observed spectra (Figure S36).

\section{FUNCTIONAL ASSESSMENT OF GLYCO-IEGMERS}

To examine the biocompatibility of glyco-IEGmers, live/dead assays using the NIH $3 \mathrm{~T} 3$ fibroblast cell line were used. No increase in cell death was observed upon exposure of cells to $5 \%$ solutions of each glyco-IEGmer for 24 or $48 \mathrm{~h}$. (Figure S29). An Alamar Blue assay using fibroblast monolayers
(Figures S30 and S31) indicated that these macromolecules have minimal influence on cellular metabolic activity. Together, these results suggest that the glyco-IEGmers have favorable toxicity properties for biological applications.

Surface plasmon resonance (SPR) measurements were used to evaluate the binding of each glyco-IEGmer to eight different surface-immobilized forms of human innate immune C-type lectins: DC-SIGN, DC-SIGNR, mannose-binding lectin (MBL), surfactant protein D (SP-D), langerin, dectin-2, mincle, and DEC-205. These eight lectins can interact with carbohydrate moieties displayed on pathogens. ${ }^{3}$ They all are members of the C-type lectin class, which means they bind their ligands using a calcium-dependent carbohydrate-recognition domain. DC-SIGN, DC-SIGNR, langerin, dectin-2, DEC-205, and mincle are transmembrane proteins that can bind and promote antigen uptake into immune cells. For example, the transmembrane DC-SIGN (CD209) is displayed on dendritic cells (DCs) and macrophages, interacting with $\mathrm{HIV}^{53}$ the homologue DC-SIGNR (L-SIGNR) is displayed on endothelial cells and can also bind to HIV and other immunodeficiency viruses. ${ }^{54}$ Langerin is specific to Langerhans cells and acts as an endocytic receptor on these subsets of dendritic cells. ${ }^{55}$ Dectin-2 (dendritic cell-associated lectin-2) also induces innate immune responses. ${ }^{56}$ Mincle (macrophage inducible C-type lectin) is an activating receptor that senses damaged cells. ${ }^{57}$ DEC-205 (CD205) is expressed by dendritic 


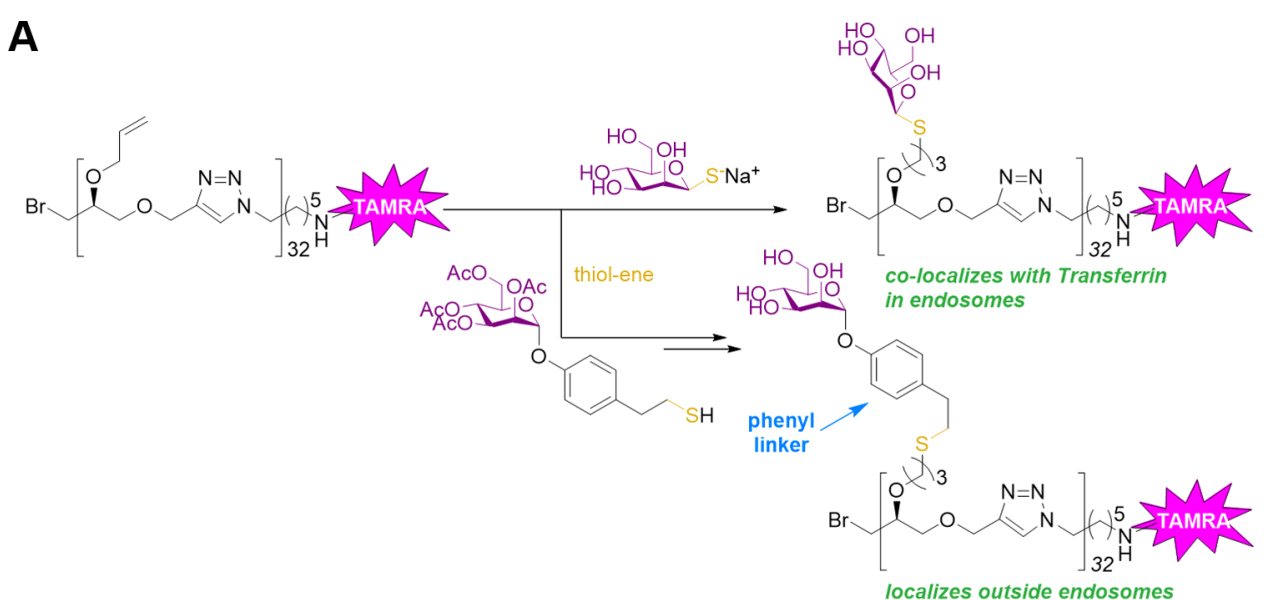

B

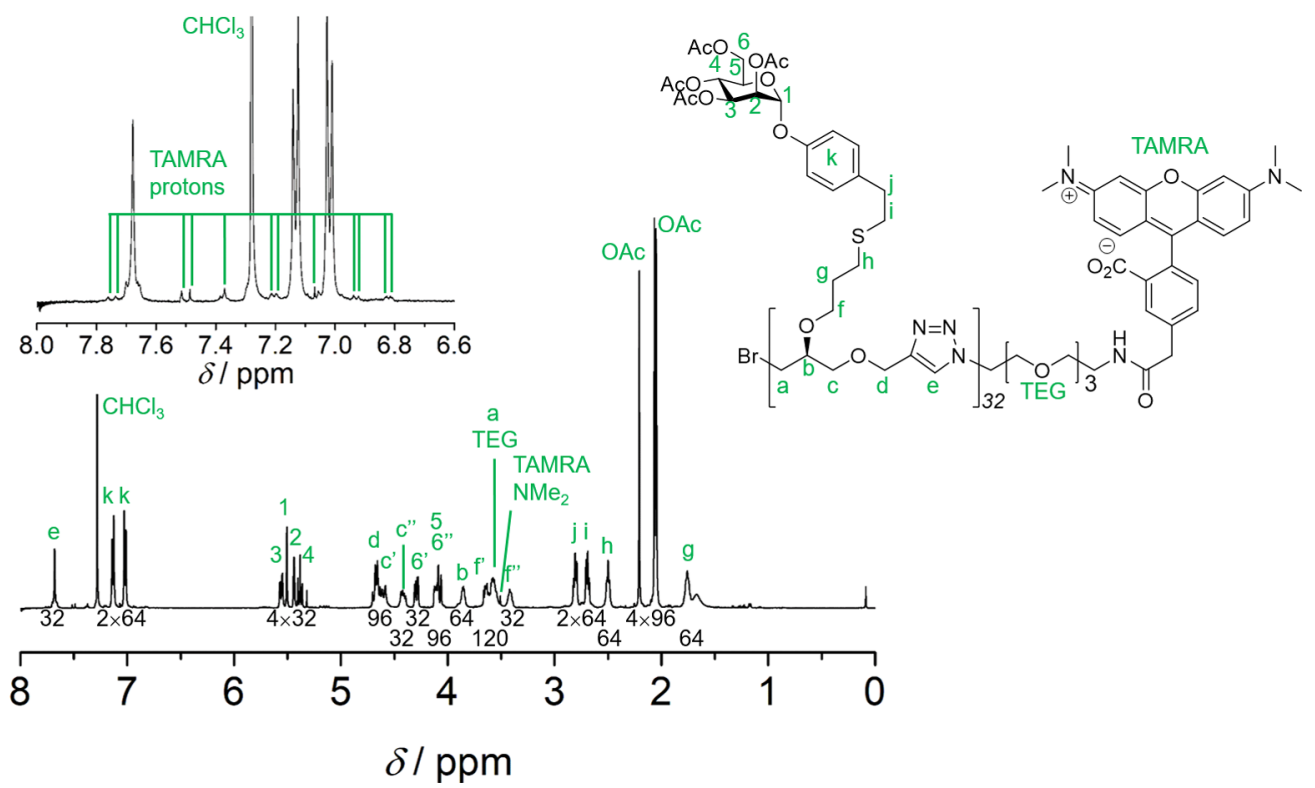

Figure 4. (A) Structures of TAMRA-tagged mannosylated glyco-IEG-32-mers without (top) and with a phenyl linker (bottom). (B) ${ }^{1} \mathrm{H}$ NMR characterization $\left(500 \mathrm{MHz}, \mathrm{CDCl}_{3}, 25^{\circ} \mathrm{C}, 400 \mathrm{MHz}\right)$ of the TAMRA-labeled-(R)-PhMan $(\mathrm{OAc})_{4}-32$-mer.

cells and epithelial cells and is thought to be involved in antigen processing. ${ }^{58}$ For these lectins, we immobilized their soluble carbohydrate recognition domains. The other two lectins, MBL, ${ }^{59}$ and SP-D, ${ }^{80}$ are soluble collectins (collagencontaining lectins) that can bind to a range of viruses or bacteria. ${ }^{59,60}$ The complete SPR curves for each glyco-IEGmer $(1-16 \mu \mathrm{M})$ and lectin (see the Supporting Information) were used to calculate association rate constants $\left(k_{\mathrm{a}}\right)$, dissociation rate constants $\left(k_{\mathrm{d}}\right)$, binding affinity constants $\left(K_{\mathrm{A}}\right)$, and maximum binding responses $\left(R_{\max }\right)$ for each lectin-glycoIEGmer pair (Figure 3 and Tables S1-12).

The SPR results highlight the impacts of glyco-IEGmer length, topology, and stereochemistry in many instances. Strikingly, each of the $K_{\mathrm{A}}$ values ranged from $\sim 1 \times 10^{4}$ to $1 \times$ $10^{9}$, with $2-5$ orders-of-magnitude differences for each lectin (Figure $3 \mathrm{~A}$ ) or glyco-IEGmer (Figure $3 \mathrm{~B}$ ). For example, $K_{\mathrm{A}}$ values for DC-SIGN ranged from approximately $1 \times 10^{4}$ for (S)-8mer to about $1 \times 10^{8}$ for $(R)-16$ mer. For dectin-2, the values range from $\sim 1 \times 10^{4}$ for $(R)-8$ mer to $\sim 1 \times 10^{8}$ for $(R$ alt-S)-16mer and each of the diastereomeric 32mers. DEC-205 bound all of the glyco-IEGmers with high $K_{\mathrm{A}}$ values in the range of $\sim 1 \times 10^{6}$ to $1 \times 10^{9}$, with $(R)$-32mer showing the highest $K_{\mathrm{A}}$ of all pairwise interactions tested $\left(2.2 \times 10^{9} \mathrm{M}^{-1}\right)$.
This range is impressive as the mannose binding epitopes presented was identical.

Analysis of glyco-IEG potency reveals that longer oligomers generally have higher activity, though not always (Figure 3 and Table S12). For example, in the case of DC-SIGN, the 16mers had $K_{\mathrm{A}}$ values $\sim 10$-fold larger than the 32 mers. For langerin, the $K_{\mathrm{A}}$ value for the $(S)$ linear 8-mer was larger $\left(K_{\mathrm{A}}=4.7 \times\right.$ $\left.10^{7} \mathrm{M}^{-1}\right)$ than the $K_{\mathrm{A}}$ values of the $(S)-16 \mathrm{mer}\left(K_{\mathrm{A}}=4.0 \times 10^{6}\right.$ $\left.\mathrm{M}^{-1}\right)$ or the $(S)-32 \mathrm{mer}\left(K_{\mathrm{A}}=3.6 \times 10^{7} \mathrm{M}^{-1}\right)$. Thus, while the multivalent effect generally held, the ability to synthesize and evaluate discrete glyco-IEGmers revealed important exceptions that may be obfuscated using disperse glycopolymer mixtures.

The macrocyclic glyco-IEGmers ("8mer MC" samples) generally showed greater $K_{\mathrm{A}}$ and $R_{\max }$ values than their linear counterparts, perhaps due to their greater rigidity and the corresponding reduced entropic penalty for binding. ${ }^{61,62}$ For example, despite displaying 4-fold fewer mannose ligands, $(R$ alt-S)-8mer MC bound to all eight lectins with $R_{\max }$ values similar to those of the linear (R-alt-S)-32mer. Although the macrocyclic 8-mers displayed higher $K_{\mathrm{a}}$ values with DC-SIGN, MBL, SP-D, dectin-2, and mincle than their linear counterparts (e.g., by up to 4 orders of magnitude for dectin-2), the latter displayed higher binding affinities for DC-SIGNR (with the 
A

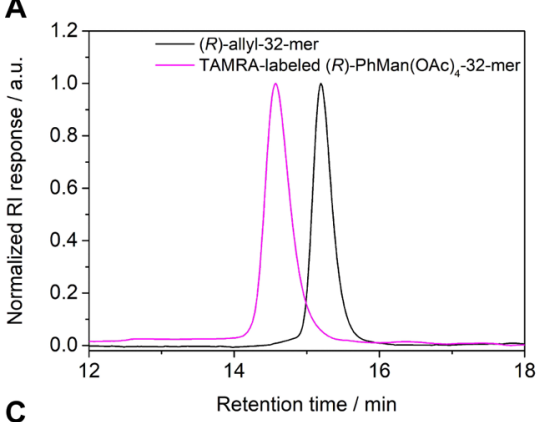

C

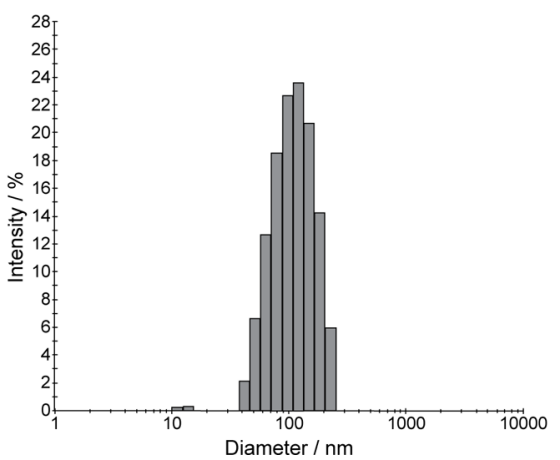

B
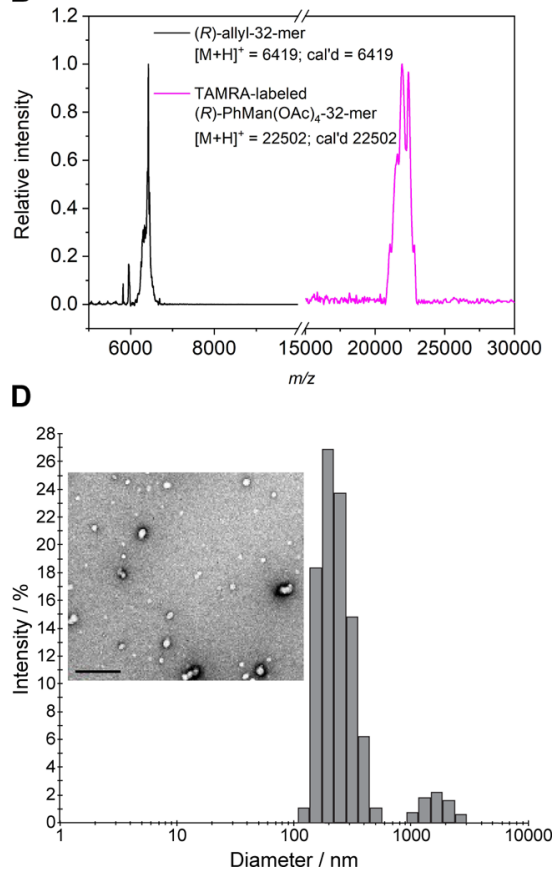

Figure 5. (A, B) GPC and MALDI-ToF analyses, respectively, of TAMRA-labeled (R)-Man-32-mer (black) and the allyl-(R)-32-mer synthetic precursor. (C) DLS analysis of TAMRA-labeled ( $R$ )- Man-32-mer in $\mathrm{H}_{2} \mathrm{O}$. (D) DLS analysis $\left(\right.$ in $\mathrm{H}_{2} \mathrm{O}$ ) and TEM image (inset) of TAMRA-labeled PhMannose- $(R)-32$-mer. Scale bar $=500 \mathrm{~nm}$.

exception of the R-alt-S macrocycle) and DEC-205. These data indicate cyclic topology alone does not always lead to stronger binding, suggesting that stereochemical features also play a key role. The $\mathrm{MD}$ results provide qualitative support for this assertion (Figure 2), indicating that each glyco-IEGmer backbone configuration and topology affords a distinct set of discrete conformational substates, each of which presents the mannose groups in unique orientations. Experimentally, significant differences in binding affinity for different backbone absolute configurations were observed (Figure 3). For example, the macrocyclic (R-alt-S) 8-mer bound more tightly than its diastereomers or linear (R-alt-S) counterparts to almost all lectins, with $>10$-fold differences in $K_{\mathrm{A}}$ for DC-SIGN and DC-SIGNR. For DC-SIGN, the $(R)$ 8- and 16-mers have higher $K_{\mathrm{A}}$ values than their diastereomers. For MBL, the $(R)$ 8mer binds nearly two orders-of-magnitude more strongly than the $(S)$ diastereomer, whereas the (R-alt-S) 16-mer binds more strongly than its diastereomers. In general, although stereochemistry has little effect on the binding affinity of most of the 32-mers, the 16-mers have $\sim 1-2$ orders-of-magnitude differences as a function of absolute configuration for all lectins except DEC-205. These findings illustrate the critical importance of the 3D presentation of functional groups for selective lectin binding and suggest that such effects are more prominent for shorter glyco-IEGmers.

Finally, we uncovered another key role for stereochemistry in dictating the binding affinity of glyco-IEGmers: rather than simply changing the specific $3 \mathrm{D}$ presentation of mannose groups for a given conformation, stereochemistry also affects the number, nature, and lifetime of unique conformational states that can be accessed for a given glyco-IEGmer, which impacts lectin binding. From MD, the linear and macrocyclic 8-mers (Figures S47-S52) having R-alt-S configurations generally sample more diverse conformational landscapes. Experimentally, the (R-alt-S) glyco-IEGmers of all lengths and topologies have higher binding affinities compared to their $(S)$ and $(R)$ diastereomers in most of the comparisons made across the four groups of polymers and eight lectins (19 of the 32 total comparisons, Figure 3A, black bars). These results suggest that the $(R$-alt-S) structures are more capable than their $(S)$ and $(R)$ counterparts of adopting a suitable conformation for lectin binding. Therefore, fine-tuning the interplay between stereochemistry and conformational diversity, which is possible through the IEG synthesis strategy employed here, may represent a path toward highly selective mannose-lectin binding.

In addition to evaluating the effects of topology, length, and stereochemistry on lectin binding, we used the flexibility of IEG synthesis to investigate whether side-chain composition could tune the properties of glyco-IEGmers. We assembled two different glyco-IEGmer side chain variants derived from allyl-(R)-32-mer, and compared their lectin-mediated cell uptake and trafficking. To this end, the alkyne of the allyl$(R)$-32-mer was used to install the fluorescent dye carboxytetramethylrhodamine (TAMRA). Subsequently, thiol-ene addition reactions of either thiomannose or a phenyl-mannose derivative were conducted to attach different mannose-based side chains (Figure 4A). ${ }^{1} \mathrm{H}$ NMR analysis of the acetylated TAMRA-labeled PhMannose- $(R)-32$-mer in organic solvent $\left(\mathrm{CDCl}_{3}\right)$ (Figure 4B) shows the presence of the aromatic PhMan signals between 7.2 and $7.0 \mathrm{ppm}\left(\mathrm{H}^{\mathrm{k}}\right)$, along with multiple weak signals attributed to the TAMRA end-group. GPC and MALDI-ToF analyses (Figure 5A, B, respectively) of the allyl-(R)-32mer and the fully acetylated TAMRA-labeled PhMannose- $(R)$-32-mer indicated successful side chain installation. Notably, the product polymer molar mass is $>22.5 \mathrm{kDa}$, which is quite large for a discrete synthetic polymer. The deprotected TAMRA-labeled $(R)$-Man-32mer has good solubility in water at $0.17 \mathrm{mg} / \mathrm{mL}(10 \mu \mathrm{M})$, forming $\sim 120 \mathrm{~nm}$ assemblies as determine by dynamic light scattering 
A
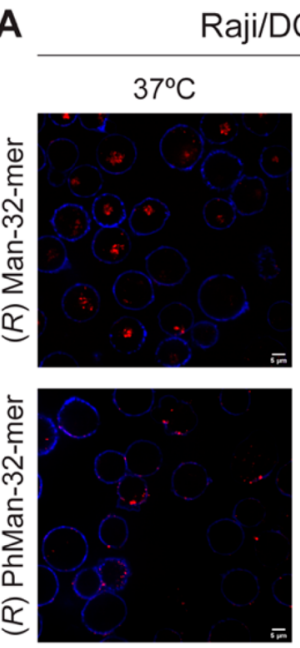

B
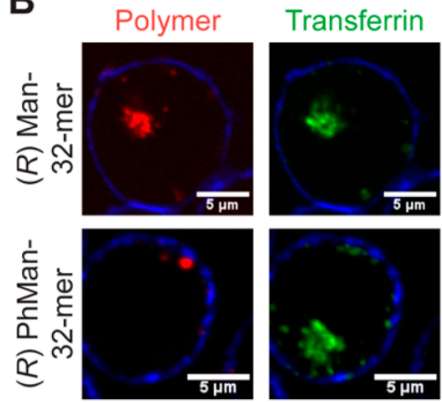

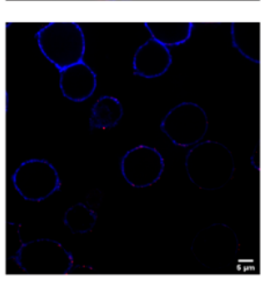

$4^{\circ} \mathrm{C}$
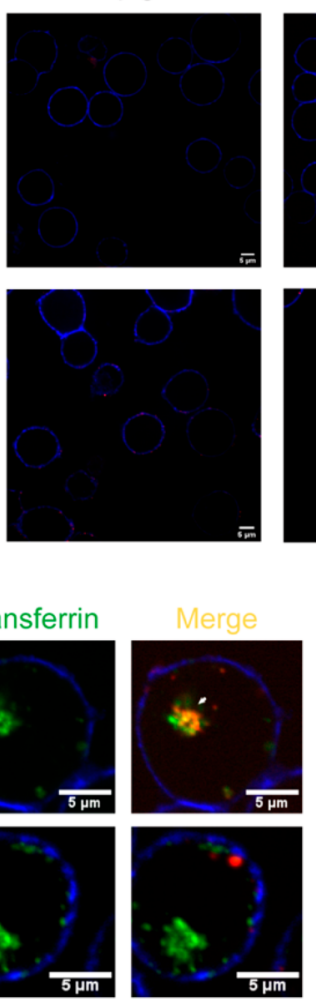

Raji
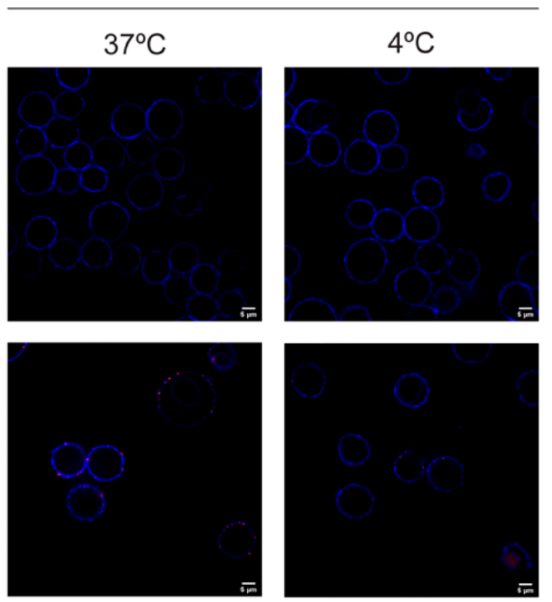

C

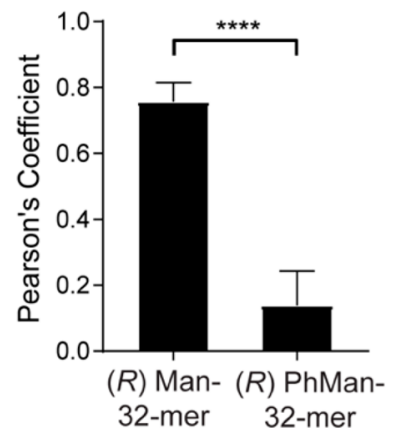

Figure 6. (A) Fluorescence microscopy images of the TAMRA-labeled ( $R$ )-PhMan-32mer and ( $R$ )-Man-32mer (red) at 4 and $37{ }^{\circ} \mathrm{C}$ in DC-SIGN modified Raji B cells (left) and DC-SIGN negative Raji B cells (right). Scale bars are $5 \mu \mathrm{m}$. (B) Fluorescence microscopy images of the TAMRAlabeled glyco-IEG-32-mers (red) and transferrin (green) in DC-SIGN modified Raj B cells and transferrin (green) in DC-SIGN modified Raj B cells. Scale bars are $5 \mu \mathrm{m}$. (C) Quantification of colocalization of glyco-IEGmers and transferrin.

(Figure 5C). The more hydrophobic phenyl-mannose derivative $^{34}$ aggregate to a greater extent in water, forming larger $\sim 240 \mathrm{~nm}$ particles (Figure 5D).

Incubation of these two fluorescently labeled glyco-IEGmers with DC-SIGN positive Raji B-cells and DC-SIGN negative Raji B-cells at either 37 or $4{ }^{\circ} \mathrm{C}$ resulted in substantial binding and/or uptake only for the DC-SIGN-positive cells at physiological temperature (Figure 6A, left column). Neither polymer interacted with the cells at $4{ }^{\circ} \mathrm{C}$. Moreover, no binding to the DC-SIGN-negative Raji B-cells at $37{ }^{\circ} \mathrm{C}$ was detected. Colocalization of TAMRA-labeled $(R)$-Man-32mer with transferrin (Figure 6B, C) suggested that this glycoIEGmer was taken up via endocytosis and localized inside endo/lysosomes. By contrast, the TAMRA-labeled $(R)$ PhMan-32mer did not colocalize with transferrin suggesting it was incorporated into invaginated pockets. Aggregation of (R)-PhMan-32mer may prevent localization in endosomes, resulting in a composition-dependent difference in trafficking as observed for other glycopolymer compositions. ${ }^{34}$

In conclusion, we established a novel approach to the efficient synthesis of discrete, chiral glyco-IEGmers with molar masses up to $\sim 22.5 \mathrm{kDa}$. These macromolecules can be manipulated precisely to preferentially bind specific human lectins. While our results confirm that increased glycan valency generally increases overall binding strength of glycomacromolecules to lectins, our results show that absolute configuration and topology (linear versus cyclic), as well as conformational diversity, substantially impact lectin binding in many cases, thus revealing that such molecular features must be considered in future glycopolymer designs especially if selective targeting is a goal. By changing the composition of the mannose side chain, we could alter the physical properties of our glycoIEGmers and their resulting trafficking. The range of lectin specificity and biological tuning exhibited here has, to our knowledge, not been demonstrated for a library of discrete synthetic glycomacromolecules before. Thus, we anticipate that this work can yield a new means of optimizing and exploiting glycan-lectin interactions, which may eventually lead to selective therapeutics or tools for chemical biology.

\section{METHODS}

\section{General Procedure for a Cycle of IEG}

The desired allyl-IEGmer with bromide and TIPS end groups was dissolved in DMF $(100 \mathrm{mg} / \mathrm{mL})$. A solution of tetrabutylammonium fluoride ( $1 \mathrm{M}$ in THF; 1.05 equiv) was added slowly. After $1 \mathrm{~h}$, the solvent was removed under reduced pressure. The crude product was dissolved in $\mathrm{CHCl}_{3}$ and purified by recycling preparatory GPC to yield the desired alkyne. Separately, $\mathrm{NaN}_{3}$ (6 equiv.) was added to a DMF solution of the same allyl-IEGmer $(100 \mathrm{mg} / \mathrm{mL})$ starting material used above. The resulting mixture was heated at $35^{\circ} \mathrm{C}$ while stirring for $24 \mathrm{~h}$. After this time, the reaction mixture was concentrated under a vacuum, diluted with EtOAc, and washed twice with water and once with brine. The organic layer was dried with $\mathrm{Na}_{2} \mathrm{SO}_{4}$ and concentrated under a vacuum, providing the desired azide. Finally, the alkyne and azide prepared above were combined in a 1:1 molar ratio with sodium ascorbate (1 equiv) and DMF (90 mg of IEGmer/mL) under a $\mathrm{N}_{2}$ atmosphere. A separate DMF solution of 
0.1 $\mathrm{M} \mathrm{CuBr}$ and 0.2 M PMDETA prepared under a $\mathrm{N}_{2}$ atmosphere was added. The resulting reaction mixture was heated at $50{ }^{\circ} \mathrm{C}$ for 24 h. After this time, the solvent was removed under reduced pressure. The viscous mixture was dissolved in a minimal amount of dichloromethane and passed through a neutral alumina column with $8 \% \mathrm{MeOH} / \mathrm{DCM}$ to remove precipitates and copper salts. The collected solution was concentrated under a vacuum, dissolved in a minimal amount of $\mathrm{CHCl}_{3}$, passed through a syringe filter, and purified by recycling preparatory GPC yielding the desired allylIEGmer.

\section{General Procedure for Azidation and Macrocyclization of} Allyl-IEG 8-mers

$\mathrm{NaN}_{3}$ (3 equiv.) was added to a solution of a desired alkyneterminated allyl-IEG octamer ( 1 equiv.) in DMF $(1.8 \mathrm{mg}$ of allylIEGmer $/ \mathrm{mL}$ ). The mixture was heated at $35{ }^{\circ} \mathrm{C}$ while stirring for 24 h. Afterward, EtOAc was added and the mixture was washed $3 \times$ with $5 \% \mathrm{LiCl}$ solution. The organic layer was concentrated to yield the desired azide, which without further purification was dissolved in DMF (0.01 M) under an $\mathrm{N}_{2}$ atmosphere. Sodium ascorbate (3 equiv.) was added followed by a solution of $0.1 \mathrm{M} \mathrm{CuBr}$ (3 equiv.) and $0.2 \mathrm{M}$ PMDETA in DMF $(0.1 \mathrm{M})$. The reaction was heated at $50{ }^{\circ} \mathrm{C}$ while stirring for 2 days. The solvent was removed under vacuum. The resulting viscous mixture was dissolved in a minimal amount of dichloromethane and passed through a neutral alumina column with $5 \% \mathrm{MeOH} / \mathrm{DCM}$ to remove precipitates and copper salts. The collected solution was concentrated under vacuum, dissolved in a minimal amount of $\mathrm{CHCl}_{3}$, passed through a syringe filter, and purified by recycling preparatory GPC, yielding the desired allyl-IEG 8 -mer macrocycle.

\section{General Procedure for Mannosylation of Allyl-IEGmers} through Thiol-ene Addition

1 -Thio- $\beta$ - $d$-mannose sodium salt (6-10 equiv./ene), a desired allylIEGmer, and DMPA (1-2 equiv./ene) were suspended in $N, N$ dimethylformamide (DMF; $100 \mathrm{mg}$ allyl-IEGmer/L). A solution of $\mathrm{HCl}$ ( 1.10 equiv./thiolate) in DMF was added. The heterogeneous mixture was irradiated with ultraviolet light $(\lambda=365 \mathrm{~nm})$ while vigorously stirring for $6 \mathrm{~h}$. Another batch of 1-thio- $\beta$ - $d$-mannose sodium salt, DMPA, $\mathrm{HCl}$, and DMF was added, and the heterogeneous mixture was irradiated for another $12 \mathrm{~h}$ while vigorously stirring. If ${ }^{1} \mathrm{H}$ NMR spectroscopy did not show full disappearance of alkene signals, another batch of 1-thio- $\beta$ - $d$-mannose sodium salt, DMPA, $\mathrm{HCl}$, and DMF was added and irradiation was continued for another $12 \mathrm{~h}$. This general process was repeated until full conversion of double bonds was observed. The crude reaction mixture was then dialyzed against $\mathrm{MeOH}, \mathrm{MeOH} / \mathrm{H}_{2} \mathrm{O}(1 / 1)(\times 2)$, and $\mathrm{H}_{2} \mathrm{O}(800 \mathrm{~mL}$ each $)$. The product was obtained after lyophilization.

\section{ASSOCIATED CONTENT}

\section{Supporting Information}

The Supporting Information is available free of charge at https://pubs.acs.org/doi/10.1021/jacsau.1c00255.

Chemical synthesis, full structural analysis of glycoIEGmers, CD spectra, SPR measurements, cytotoxicity assays (PDF)

\section{AUTHOR INFORMATION}

\section{Corresponding Authors}

Jeremiah A. Johnson - Department of Chemistry, Massachusetts Institute of Technology, Cambridge, Massachusetts 02139, United States; (1) orcid.org/00000001-9157-6491; Email: jaj2109@mit.edu

C. Remzi Becer - School of Engineering and Materials Science, Queen Mary University of London, London E1 4NS, United Kingdom; Department of Chemistry, University of
Warwick, Coventry CV4 7AL, United Kingdom; 다이.org/0000-0003-0968-6662; Email: remzi.becer@ warwick.ac.uk

Laura L. Kiessling - Department of Chemistry, Massachusetts Institute of Technology, Cambridge, Massachusetts 02139, United States; orcid.org/0000-0001-6829-1500; Email: kiesslin@mit.edu

\section{Authors}

Manuel Hartweg - Department of Chemistry, Massachusetts Institute of Technology, Cambridge, Massachusetts 02139, United States; 이이.orid.org/000-0001-9488-8001

Yivan Jiang - Department of Chemistry, Massachusetts Institute of Technology, Cambridge, Massachusetts 02139, United States

Gokhan Yilmaz - School of Pharmacy, University of Nottingham, Nottingham NG7 2RD, United Kingdom; Department of Chemistry, University of Warwick, Coventry CV4 7AL, United Kingdom

Cassie M. Jarvis - Department of Chemistry, Massachusetts Institute of Technology, Cambridge, Massachusetts 02139, United States; 이이.orid/0000-0003-4287-4163

Hung V.-T. Nguyen - Department of Chemistry, Massachusetts Institute of Technology, Cambridge, Massachusetts 02139, United States; orcid.org/00000002-6945-4057

Gastón A. Primo - School of Engineering and Materials Science, Queen Mary University of London, London E1 4NS, United Kingdom

Alessandra Monaco - Department of Chemistry, University of Warwick, Coventry CV4 7AL, United Kingdom

Valentin P. Beyer - Department of Chemistry, University of Warwick, Coventry CV4 7AL, United Kingdom

Kathleen K. Chen - Department of Chemistry, Massachusetts Institute of Technology, Cambridge, Massachusetts 02139, United States

Somesh Mohapatra - Department of Materials Science and Engineering, Massachusetts Institute of Technology, Cambridge, Massachusetts 02139, United States; (1) orcid.org/0000-0001-9498-3834

Simon Axelrod - Department of Materials Science and Engineering, Massachusetts Institute of Technology, Cambridge, Massachusetts 02139, United States

Rafael Gómez-Bombarelli - Department of Materials Science and Engineering, Massachusetts Institute of Technology, Cambridge, Massachusetts 02139, United States; (1) orcid.org/0000-0002-9495-8599

Complete contact information is available at: https://pubs.acs.org/10.1021/jacsau.1c00255

\section{Author Contributions}

${ }^{\dagger}$ M.H. and Y.J. contributed equally to this work. Y.J., J.A.J., M.H., and C.R.B. conceived of the project and designed the experiments. M.H., Y.J., H.V.T.N., and K.K.C. performed the synthesis of allyl-IEG precursors. M.H. and Y.J. performed the synthesis of the glyco-IEGmers. G.Y. and A.M. performed the SPR analysis. G.A.P. performed the 3T3 cell assays and Alvaro Mata is acknowledged for providing access to 3T3 cell assays. C.J. and L.L.K. have performed the B-cell assays. R.G.B., S.M., and S.A. conducted computer simulations. All authors analyzed the experimental data, edited, and commented on the manuscript. 


\section{Funding}

We thank the Army Research Office (W911NF-17-1-0521) and the National Institutes of Health (R01-CA220468-01) for support of this work. G.Y. was funded by EPSRC (EP/ P009018/1) and M.H. received funding from the Royal Society of Chemistry. L.L.K. acknowledges the National Institute of Allergy and Infectious Disease of the NIH for support (AI055258).

Notes

The authors declare no competing financial interest.

\section{ABBREVIATIONS}

CD209 (DC-SIGN), dendritic cell-specific ICAM-3 grabbing nonintegrin; DC-SIGNR, DC-SIGN-related; langerin, CD207; MBL, mannose-binding lectin; SP-D, pulmonary surfactant protein $\mathrm{D}$; dectin-2, dendritic cell-associated C-type lectin; mincle, macrophage inducible $\mathrm{Ca}^{2+}$-dependent lectin receptor; DEC-205, CD205

\section{REFERENCES}

(1) Stillmark, P. H. Ph.D. Dissertation; University of Dorpat, Tartu, Estonia, 1888.

(2) Boyd, W. C.; Shapleigh, E. Specific Precipitating Activity of Plant Agglutinins (Lectins). Science 1954, 119, 419.

(3) Figdor, C. G.; van Kooyk, Y.; Adema, G. J. C-Type Lectin Receptors on Dendritic Cells. Nat. Rev. Immunol. 2002, 2, 77-84.

(4) Varki, A. Biological Roles of Glycans. Glycobiology 2017, 27, 349.

(5) Sharon, N.; Lis, H. Lectins as Cell Recognition Molecules. Science 1989, 246, 227-234.

(6) Weis, W.; Drickamer, K. Structural Basis of Lectin-Carbohydrate Recognition. Annu. Rev. Biochem. 1996, 65, 441-473.

(7) Rüdiger, H.; Gabius, H. J. Plant Lectins: Occurrence, Biochemistry, Functions and Applications. Glycoconjugate J. 2001, $18,589-613$.

(8) Liener, I. E.; Sharon, N.; Goldstein, I. J. The Lectins. Properties, Functions, and Applications in Biology and Medicine; Academic Press, Orlando, 1986.

(9) Gabius, H. J. Animal Lectins. Eur. J. Biochem. 1997, 243, 543576.

(10) Lundquist, J. J.; Toone, E. J. The Cluster Glycoside Effect. Chem. Rev. 2002, 102, 555-578.

(11) Kiessling, L. L.; Gestwicki, J. E.; Strong, L. E. Synthetic Multivalent Ligands as Probes of Signal Transduction. Angew. Chem., Int. Ed. 2006, 45, 2348-2368.

(12) Lepenies, B.; Lee, J.; Sonkaria, S. Targeting C-Type Lectin Receptors with Multivalent Carbohydrate Ligands. Adv. Drug Delivery Rev. 2013, 65, 1271-1281.

(13) Spain, S. G.; Gibson, M. I.; Cameron, N. R. Recent Advances in the Synthesis of Well-Defined Glycopolymers SEBASTIAN. J. Polym. Sci., Part A: Polym. Chem. 2007, 45, 2059-2072.

(14) Stine, K. J. Carbohydrate Nanotechnology; John Wiley \& Sons: Hoboken, NJ, 2016.

(15) Vyas, N. K. Atomic Features of Protein-Carbohydrate Interactions. Curr. Opin. Struct. Biol. 1991, 1, 732-740.

(16) Kiessling, L. L.; Splain, R. A. Chemical Approaches to Glycobiology. Annu. Rev. Biochem. 2010, 79, 619-653.

(17) Nycholat, C. M.; Peng, W.; McBride, R.; Antonopoulos, A.; De Vries, R. P.; Polonskaya, Z.; Finn, M. G.; Dell, A.; Haslam, S. M.; Paulson, J. C. Synthesis of Biologically Active N-Ando-Linked Glycans with Multisialylated Poly-n-Acetyllactosamine Extensions Using p. Damsela A2-6 Sialyltransferase. J. Am. Chem. Soc. 2013, 135, 1828018283.

(18) Mortell, K. H.; Weatherman, R. V.; Kiessling, L. L. Recognition Specificity of Neoglycopolymers Prepared by Ring-Opening Metathesis Polymerization. J. Am. Chem. Soc. 1996, 118, 2297-2298.
(19) Strong, L. E.; Kiessling, L. L. A General Synthetic Route to Defined, Biologically Active Multivalent Arrays. J. Am. Chem. Soc. 1999, 121, 6193-6196.

(20) Ambrosi, M.; Cameron, N. R.; Davis, B. G.; Stolnik, S. Investigation of the Interaction between Peanut Agglutinin and Synthetic Glycopolymeric Multivalent Ligands. Org. Biomol. Chem. 2005, 3, 1476-1480.

(21) Pasparakis, G.; Cockayne, A.; Alexander, C. Control of Bacterial Aggregation by Thermoresponsive Glycopolymers. J. Am. Chem. Soc. 2007, 129, 11014-11015.

(22) Becer, C. R.; Gibson, M. I.; Geng, J.; Ilyas, R.; Wallis, R.; Mitchell, D. A.; Haddleton, D. M. High-Affinity Glycopolymer Binding to Human DC-SIGN and Disruption of DC-SIGN Interactions with HIV Envelope Glycoprotein. J. Am. Chem. Soc. 2010, 132, 15130-15132.

(23) Zhou, M.; Delaveris, C. S.; Kramer, J. R.; Kenkel, J. A.; Engleman, E. G.; Bertozzi, C. R. N-Carboxyanhydride Polymerization of Glycopolypeptides That Activate Antigen Presenting Cells through Dectin-1 and -2. Angew. Chem., Int. Ed. 2018, 57, 3137-3142.

(24) Mochalova, L. V.; Tuzikov, A. B.; Marinina, V. P.; Gambaryan, A. S.; Byramova, N. E.; Bovin, N. V.; Matrosovich, M. N. Synthetic Polymeric Inhibitors of Influenza Virus Receptor-Binding Activity Suppress Virus Replication. Antiviral Res. 1994, 23, 179-190.

(25) Mammen, M.; Choi, S.; Whitesides, G. M. Polyvalent Interactions in Biological Systems: Implications for Design and Use of Multivalent Ligands and Inhibitors. Angew. Chem., Int. Ed. 1998, 37, 2754-2794.

(26) Haldar, J.; Álvarez De Cienfuegos, L.; Tumpey, T. M.; Gubareva, L. V.; Chen, J.; Klibanov, A. M. Bifunctional Polymeric Inhibitors of Human Influenza a Viruses. Pharm. Res. 2010, 27, 259263.

(27) Nagao, M.; Fujiwara, Y.; Matsubara, T.; Hoshino, Y.; Sato, T.; Miura, Y. Design of Glycopolymers Carrying Sialyl Oligosaccharides for Controlling the Interaction with the Influenza Virus. Biomacromolecules 2017, 18, 4385-4392.

(28) McReynolds, K. D.; Gervay-Hague, J. Chemotherapeutic Interventions Targeting HIV Interactions with Host-Associated Carbohydrates. Chem. Rev. 2007, 107, 1533-1552.

(29) Zhang, Q.; Collins, J.; Anastasaki, A.; Wallis, R.; Mitchell, D. A.; Becer, C. R.; Haddleton, D. M. Sequence-Controlled Multi-Block Glycopolymers to Inhibit DC-SIGN-Gp120 Binding. Angew. Chem., Int. Ed. 2013, 52, 4435-4439.

(30) Varga, N.; Sutkeviciute, I.; Ribeiro-Viana, R.; Berzi, A.; Ramdasi, R.; Daghetti, A.; Vettoretti, G.; Amara, A.; Clerici, M.; Rojo, J.; et al. Biomaterials A Multivalent Inhibitor of the DC-SIGN Dependent Uptake of HIV-1 and Dengue Virus. Biomaterials 2014, $35,4175-4184$.

(31) Zhang, Q.; Su, L.; Collins, J.; Chen, G.; Wallis, R.; Mitchell, D. A.; Haddleton, D. M.; Becer, C. R. Dendritic Cell Lectin-Targeting Sentinel-like Unimolecular Glycoconjugates to Release an Anti-HIV Drug. J. Am. Chem. Soc. 2014, 136, 4325-4332.

(32) Mitchell, D. A.; Zhang, Q.; Voorhaar, L.; Haddleton, D. M.; Herath, S.; Gleinich, A. S.; Randeva, H. S.; Crispin, M.; Lehnert, H.; Wallis, R.; et al. Manipulation of Cytokine Secretion in Human Dendritic Cells Using Glycopolymers with Picomolar Affinity for DCSIGN. Chem. Sci. 2017, 8, 6974-6980.

(33) Yilmaz, G.; Uzunova, V.; Hartweg, M.; Beyer, V.; Napier, R.; Becer, C. R. The Effect of Linker Length on ConA and DC-SIGN Binding of: S -Glucosyl Functionalized Poly(2-Oxazoline)S. Polym. Chem. 2018, 9, 611-618.

(34) Jarvis, C. M.; Zwick, D. B.; Grim, J. C.; Prost, L. R.; Alam, M. M.; Gardiner, J. C.; Park, S.; Zimdars, L. L.; Sherer, N. M.; Kiessling, L. L. Antigen Structure Affects Cellular Routing through DC-SIGN. Proc. Natl. Acad. Sci. U. S. A. 2019, 116, 14862-14867.

(35) Geng, J.; Mantovani, G.; Tao, L.; Nicolas, J.; Chen, G.; Wallis, R.; Mitchell, D. A.; Johnson, B. R. G.; Evans, S. D.; Haddleton, D. M. Site-Directed Conjugation of "Clicked" Glycopolymers to Form Glycoprotein Mimics: Binding to Mammalian Lectin and Induction of Immunological Function. J. Am. Chem. Soc. 2007, 129, 15156-15163. 
(36) Tacken, P. J.; de Vries, I. J. M.; Torensma, R.; Figdor, C. G. Dendritic-Cell Immunotherapy: From Ex Vivo Loading to in Vivo Targeting. Nat. Rev. Immunol. 2007, 7, 790-802.

(37) Geijtenbeek, T. B. H.; Gringhuis, S. I. C-type Lectin Receptors in the Control of T Helper Cell Differentiation. Nat. Rev. Immunol. 2016, 16, 433-448.

(38) Alam, M. M.; Jarvis, C. M.; Hincapie, R.; Mckay, C. S.; Schimer, J.; Sanhueza, C. A.; Xu, K.; Diehl, R. C.; Finn, M. G.; Kiessling, L. L. Glycan-Modi Fi Ed Virus-like Particles Evoke T Helper Type 1 - like Immune Responses. ACS Nano 2021, 15, 309321.

(39) Becer, C. R. The Glycopolymer Code: Synthesis of Glycopolymers and Multivalent Carbohydrate-Lectin Interactions. Macromol. Rapid Commun. 2012, 33, 742-752.

(40) Zanini, D.; Roy, R. Chemoenzymatic Synthesis and Lectin Binding Properties of Dendritic N-Acetyllactosamine. Bioconjugate Chem. 1997, 8, 187-192.

(41) Lavilla, C.; Yilmaz, G.; Uzunova, V.; Napier, R.; Becer, C. R.; Heise, A. Block-Sequence-Specific Glycopolypeptides with Selective Lectin Binding Properties. Biomacromolecules 2017, 18, 1928-1936.

(42) Yilmaz, G.; Becer, C. R. Glycopolymer Code Based on WellDefined Glycopolymers or Glyconanomaterials and Their Biomolecular Recognition. Front. Bioeng. Biotechnol. 2014, 2, 1-18.

(43) Ponader, D.; Wojcik, F.; Beceren-Braun, F.; Dernedde, J.; Hartmann, L. Sequence-Defined Glycopolymer Segments Presenting Mannose: Synthesis and Lectin Binding Affinity. Biomacromolecules 2012, 13, 1845-1852.

(44) Ponader, D.; Maffre, P.; Aretz, J.; Pussak, D.; Ninnemann, N. M.; Schmidt, S.; Seeberger, P. H.; Rademacher, C.; Nienhaus, G. U.; Hartmann, L. Carbohydrate-Lectin Recognition of Sequence-Defined Heteromultivalent Glycooligomers. J. Am. Chem. Soc. 2014, 136, 2008-2016.

(45) Gerke, C.; Ebbesen, M. F.; Jansen, D.; Boden, S.; Freichel, T.; Hartmann, L. Sequence-Controlled Glycopolymers via Step-Growth Polymerization of Precision Glycomacromolecules for Lectin Receptor Clustering. Biomacromolecules 2017, 18, 787-796.

(46) Jacobi, F.; Camaleno de la Calle, A.; Boden, S.; Grafmuller, A.; Hartmann, L.; Schmidt, S. Multivalent Binding of Precision Glycooligomers on Soft Glycocalyx Mimicking Hydrogels. Biomacromolecules 2018, 19, 3479-3488.

(47) Gestwicki, J. E.; Cairo, C. W.; Strong, L. E.; Oetjen, K. A.; Kiessling, L. L. Influencing Receptor - Ligand Binding Mechanisms with Multivalent Ligand Architecture. J. Am. Chem. Soc. 2002, 124, 14922-14933.

(48) Binauld, S.; Damiron, D.; Connal, L. A.; Hawker, C. J.; Drockenmuller, E. Precise Synthesis of Molecularly Defined Oligomers and Polymers by Orthogonal Iterative Divergent/ Convergent Approaches. Macromol. Rapid Commun. 2011, 32, 147168.

(49) Leibfarth, F. A.; Johnson, J. A.; Jamison, T. F. Scalable Synthesis of Sequence-Defined, Unimolecular Macromolecules by Flow-IEG. Proc. Natl. Acad. Sci. U. S. A. 2015, 112, 10617-10622.

(50) Barnes, J. C.; Ehrlich, D. J. C.; Gao, A. X.; Leibfarth, F. A.; Jiang, Y.; Zhou, E.; Jamison, T. F.; Johnson, J. A. Iterative Exponential Growth of Stereo- and Sequence-Controlled Polymers. Nat. Chem. 2015, 7, 810-815.

(51) Jiang, Y.; Golder, M. R.; Nguyen, H. V. T.; Wang, Y.; Zhong, M.; Barnes, J. C.; Ehrlich, D. J. C.; Johnson, J. A. Iterative Exponential Growth Synthesis and Assembly of Uniform Diblock Copolymers. J. Am. Chem. Soc. 2016, 138, 9369-9372.

(52) Golder, M. R.; Jiang, Y.; Teichen, P. E.; Nguyen, H. V. T.; Wang, W.; Milos, N.; Freedman, S. A.; Willard, A. P.; Johnson, J. A. Stereochemical Sequence Dictates Unimolecular Diblock Copolymer Assembly. J. Am. Chem. Soc. 2018, 140, 1596-1599.

(53) Geijtenbeek, T. B. H.; Kwon, D. S.; Torensma, R.; Van Vliet, S. J.; Van Duijnhoven, G. C. F.; Middel, J.; Cornelissen, I. L. M. H. A.; Nottet, H. S. L. M.; KewalRamani, V. N.; Littman, D. R.; et al. DCSIGN, a Dendritic Cell-Specific HIV-1-Binding Protein That Enhances Trans-Infection of T Cells. Cell 2000, 100, 587-597.
(54) Pöhlmann, S.; Soilleux, E. J.; Baribaud, F.; Leslie, G. J.; Morris, L. S.; Trowsdale, J.; Lee, B.; Coleman, N.; Doms, R. W. DC-SIGNR, a DC-SIGN Homologue Expressed in Endothelial Cells, Binds to Human and Simian Immunodeficiency Viruses and Activates Infection in Trans. Proc. Natl. Acad. Sci. U. S. A. 2001, 98, 2670-2675.

(55) Valladeau, J.; Ravel, O.; Dezutter-Dambuyant, C.; Moore, K.; Kleijmeer, M.; Liu, Y.; Duvert-Frances, V.; Vincent, C.; Schmitt, D.; Davoust, J.; et al. Langerin, a Novel C-Type Lectin Specific to Langerhans Cells, Is an Endocytic Receptor that Induces the Formation of Birbeck Granules. Immunity 2000, 12, 71-81.

(56) Sato, K.; Yang, X. L.; Yudate, T.; Chung, J. S.; Wu, J.; LubyPhelps, K.; Kimberly, R. P.; Underhill, D.; Cruz, P. D.; Ariizumi, K. Dectin-2 Is a Pattern Recognition Receptor for Fungi That Couples with the Fc Receptor $\gamma$ Chain to Induce Innate Immune Responses. J. Biol. Chem. 2006, 281, 38854-38866.

(57) Yamasaki, S.; Ishikawa, E.; Sakuma, M.; Hara, H.; Ogata, K.; Saito, T. Mincle Is an ITAM-Coupled Activating Receptor That Senses Damaged Cells. Nat. Immunol. 2008, 9, 1179-1188.

(58) Jiang, W.; Swiggard, W. J.; Heufler, C.; Peng, M.; Mirza, A.; Steinman, R. M.; Nussenzweig, M. C. The receptor DEC-205 expressed by dendritic cells and thymic epithelial cells is involved in antigen processing. Nature 1995, 375, 151-155.

(59) Ji, X.; Olinger, G. G.; Aris, S.; Chen, Y.; Gewurz, H.; Spear, G. T. Mannose-Binding Lectin Binds to Ebola and Marburg Envelope Glycoproteins, Resulting in Blocking of Virus Interaction with DCSIGN and Complement-Mediated Virus Neutralization. J. Gen. Virol. 2005, 86, 2535-2542.

(60) Sano, H.; Kuroki, Y. The Lung Collectins, SP-A and SP-D, Modulate Pulmonary Innate Immunity. Mol. Immunol. 2005, 42, 279-287.

(61) Joo, S. H. Cyclic Peptides as Therapeutic Agents and Biochemical Tools. Biomol. Ther. 2012, 20, 19-26.

(62) Alaofi, A.; On, N.; Kiptoo, P.; Williams, T. D.; Miller, D. W.; Siahaan, T. J. Comparison of Linear and Cyclic HAV Peptides in Modulating the Blood-Brain Barrier Permeability: Impact on Delivery of Molecules to the Brain. J. Pharm. Sci. 2016, 105, 797-807. 